\title{
Qualidade de Silagens de Híbridos de Sorgo (Soghum bicolor (L.) Moench) de Portes Baixo, Médio e Alto com Diferentes Proporções de Colmo+Folhas/Panícula. 1. Avaliação do Processo Fermentativo
}

\author{
Fabiano Ferreira da Silva1, Lúcio Carlos Gonçalves ${ }^{2}$, José Avelino Santos Rodrigues ${ }^{3}$, Clóvis \\ Eduardo S. Corrêa ${ }^{4}$, Norberto Mário Rodriguez², André F. Brito ${ }^{5}$, Gerson B. Mourão ${ }^{4}$
}

\begin{abstract}
RESUMO - O objetivo deste experimento foi avaliar a qualidade fermentativa de silagens de sorgo de portes baixo, médio e alto, com diferentes combinações de colmo+folhas/panícula (100:00, 80:20, 60:40, 40:60, 20:80 e 00:100), por meio de análises laboratoriais. A planta inteira foi utilizada como controle. Os híbridos foram cultivados e ensilados aos 104 dias de idade em silos de laboratório de PVC, com $10 \mathrm{~cm}$ de diâmetro e $40 \mathrm{~cm}$ de comprimento (três repetições por tratamento). Os silos foram abertos aos 56 dias após a ensilagem. Os teores de matéria seca (MS), carboidratos solúveis, nitrogênio amoniacal $\left(\mathrm{N}-\mathrm{NH}_{3}\right)$ e $\mathrm{pH}$ foram determinados. As diferenças foram verificadas por intermédio do teste $\mathrm{SNK}$. Os valores de $\mathrm{pH}$ das silagens foram, em média, 3,79 e os teores de $\mathrm{N}-\mathrm{NH}_{3} /$ nitrogênio total foram inferiores a $8 \%$ em todos os tratamentos. Os teores de MS das silagens variaram de 19,40 a 49,40\%, mas todos os tratamentos conservaram-se bem de acordo com $\mathrm{pH}$ e N-NH . As densidades dos silos foram maiores com o aumento da participação da panícula. Os valores de carboidratos solúveis do material original foram baixos para a maioria dos tratamentos, porém isto não prejudicou a fermentação da massa ensilada.
\end{abstract}

Palavras-chave: qualidade, relação colmo+folhas/panícula, silagem, sorgo

\section{Silage Quality of Sorghum's Hybrids (Sorghum bicolor (L.) Moench) of Small, Medium and High Size with Different Stem+Leafs/Head Proportions. 1. Fermentative Process Evaluation}

\begin{abstract}
The objective of this experiment was to evaluate the fermentative quality of sorghum silage of small, medium and high size with different stem+leafs/head proportions (100:00, 80:20, 60:40, 40:60, 20:80, 00:100), by means of lab analysis. The whole plant was used as control. The hybrids were cultivated and ensiled at 104 days of age in PVC lab silos measuring 10-cm of diameter by 40 -cm of length (three replications per treatment). Silos were opened 56 days after the ensilage. The contents of dry matter (DM), soluble carbohydrates, ammonia nitrogen $\left(\mathrm{N}_{-} \mathrm{NH}_{3}\right)$ and $\mathrm{pH}$ were determined. Differences were compared using SNK statistical test. Average silage $\mathrm{pH}$ value was 3.79 and N$\mathrm{NH}_{3}$ /total nitrogen values were lower than $8 \%$ for all treatments. Silage's DM values varied from 19.40 to $49.40 \%$, but all treatments were well conserved considering $\mathrm{pH}$ and $\mathrm{N}_{-} \mathrm{NH}_{3}$. Silos densities were greater with the increase of head proportion. Original material soluble carbohydrate values were low for the majority of the treatments, but this did not prejudice the fermentation of the ensiled mass.
\end{abstract}

Key Words: quality, stem+leafs/head proportion, silage, sorghum

\section{Introdução}

A crescente utilização do milho na alimentação humana e de monogástricos tem aumentado o interesse pelo estudo de alternativas viáveis para a alimentação de ruminantes. O sorgo, por suas características de cultivo e valor nutritivo semelhantes aos do milho, vem sendo estudado como substituto deste cereal, principalmente como silagem (ALVARENGA, 1993). A cultura de sorgo contribui com, aproximadamente, 10 a $12 \%$ da área total cultivada para silagem no Brasil (ZAGO, 1991).
O sorgo se destaca pela sua produção elevada, bom valor nutritivo, maior tolerância a déficit hídrico ocasional (PEREIRA et al., 1989) e pela possibilidade de rebrota que pode produzir até $60 \%$ da produção de matéria seca do primeiro corte (ZAGO, 1991). Segundo o mesmo autor, para um programa de melhoramento do sorgo, além das características agronômicas (altura da planta, produtividade, resistência a doenças e pragas, entre outros), outras características devem ser consideradas: relação colmo-folhapanícula, suculência do colmo (seco x suculento), teor 
de açúcar (sorgo doce x sorgo não doce), cerosidade (presença $x$ ausência de cera) e tanino (presença $x$ ausência).

GOURLEY e LUSK (1977) encontraram proporções de colmo na planta de sorgo variando de 17,1 a $72,8 \%$ na MS, as proporções de folhas de 17,4 a $26,3 \%$ e as proporções de panículas de 5,2 a 64,6\%. A grande variação destes valores decorrem da grande variabilidade genética dos materiais utilizados, o que indica a viabilidade de se produzir planta ideal para ensilagem. PAIVA (1976) relata que silagens de milho muito boas devem ter de 30 a $35 \%$ de MS, pois este teor favorece o desenvolvimento de fermentações láticas (VAN SOEST, 1994). MEESKE et al. (1993), entretanto, obtiveram silagens bem preservadas, ensilando híbridos de sorgo com teores de MS variando de 20 a 29\%. Todavia, Bastiman (1976), citado por McDONALD et al. (1991), verificou que o teor de MS do material ensilado deve ser superior a $25 \%$ para evitar maiores perdas por intermédio dos efluentes. Em silagens com altos teores de MS ( $>35 \%)$, o pH é menos importante, pois o desenvolvimento de acidez é inibido pela falta de água e pela alta pressão osmótica, de forma que silagens com $\mathrm{pH}$ alto podem ter boa qualidade (VAN SOEST, 1994). Outro fator que contribui para boa preservação da silagem é o teor de carboidratos solúveis do material a ser ensilado, pois este nutriente é prontamente disponível para as bactérias, propiciando grande produção de ácido lático e rápida queda de $\mathrm{pH}$. Segundo LINDEN et al. (1987), sorgos sacarinos podem atingir teores totais de açúcares superiores a $20 \%$ na MS, enquanto os sorgos graníferos atingem somente 5 a $6 \%$. GOURLEY e LUSK (1977) obtiveram teores de carboidratos solúveis de 22,6; 13,8; 7,2; e $7,6 \%$ para sorgos de portes alto, médio e baixo e para o milho, respectivamente. Nesta mesma linha de pesquisa, BORGES (1995), NOGUEIRA (1995) e BERNARDINO (1996), analisando sorgos de portes alto, baixo e médio, relataram valores de carboidratos solúveis de 18,$1 ; 10,4$; e 8,2\%, respectivamente.

A dosagem de PB (CUNNIFF, 1995) em silagens é de pouco significado nutricional, pois não leva em conta as alterações na fração nitrogenada, que ao final da ensilagem pode apresentar conteúdo de proteína de até 30\% do nitrogênio total (McDONALD et al., 1991). Segundo McKERSIE (1985), a eficiência de utilização do nitrogênio pelos ruminantes alimentados com silagem rica em nitrogênio não-protéico solúvel é reduzida.

Os sorgos podem ser do tipo anão granífero, que pode conter $60 \%$ de grãos, de dupla finalidade com 20 a $30 \%$ de grãos, e do tipo forrageiro, que quase não produz grãos (SILVA et al., 1978). Então, de acordo com o tipo de sorgo, as silagens poderão apresentar variações em seu valor nutritivo.

Este experimento visou determinar a proporção ideal de colmo+folhas/panícula da planta de sorgo para produção de silagem, por meio da avaliação da qualidade fermentativa de silagens de híbridos de sorgo de portes baixo, médio e alto, em condições de laboratório.

\section{Material e Métodos}

Foram utilizados três híbridos de sorgo de portes baixo, médio e alto, com diferentes proporções de colmo+folhas/panícula, com três repetições por tratamento. Os híbridos de sorgo testados foram: BR 303 (granífero - H1), BR 601 (forrageiro - H3) e CMSXS 756 (duplo propósito - H2), produzidos pelo CNPMS/EMBRAPA. Para cada híbrido, foram utilizadas sete proporções, em relação ao peso verde, de colmo+folhas/panícula, sendo:

$1-100 \%$ panícula $\times 0 \%$ colmo+folhas;

2 - $80 \%$ panícula $\times 20 \%$ colmo+folhas;

$3-60 \%$ panícula $\times 40 \%$ colmo+folhas;

$4-40 \%$ panícula $\times 60 \%$ colmo+folhas;

$5-20 \%$ panícula $\times 80 \%$ colmo+folhas;

6 - $0 \%$ panícula $\times 100 \%$ colmo + folhas; e

7 - Planta inteira.

O sorgo foi cortado manualmente, rente ao solo, com os grãos no estádio farináceo, sendo posteriormente picado em picadeira estacionária Nogueira, modelo DPM-4, e imediatamente ensilado. As diferentes proporções de colmo+folhas e panícula foram montadas após separação destas partes, a aproximadamente $10 \mathrm{~cm}$ da base da panícula, sendo posteriormente pesadas as quantidades desejadas de cada parte, picadas, misturadas e ensiladas. Utilizaram-se 21 silos por híbrido, totalizando 63, feitos de "PVC", com $10 \mathrm{~cm}$ de diâmetro e $40 \mathrm{~cm}$ de comprimento. A compactação foi feita com êmbulo de madeira e o fechamento com tampas de "PVC", dotadas de válvulas tipo "Bunsen". Os silos foram lacrados com fita crepe e tarados e pesados após seu fechamento. Parte do material picado foi amostrado para ser analisado como forragem original. Os silos foram abertos após 56 dias de ensilados. As amostras (material original e silagem) foram pré-secas em estufa de ventilação forçada a $60-65^{\circ} \mathrm{C}$, por 72 horas e moídas em moinho estacionário "Thomas-Wiley", modelo 4, utilizando-se peneira de $1 \mathrm{~mm}$. Em seguida, foram guardadas em vidros com tampa para as de- 
16 Rev. bras. zootec.

mais determinações laboratoriais. O restante do material retirado de cada silo foi prensado utilizando-se prensa hidráulica "Carver", modelo C, para extração do suco que foi utilizado imediatamente para análise do nitrogênio amoniacal $\left(\mathrm{N}-\mathrm{NH}_{3}\right)$ e $\mathrm{pH}$. O teor de N$\mathrm{NH}_{3}$, como porcentagem do N-Total, foi dosado imediatamente após a extração do suco, utilizando-se de óxido de magnésio e cloreto de cálcio, segundo CUNNIFF (1995), assim como o $\mathrm{pH}$, por intermédio do potenciômetro "Beckman Expandomatic SS-2" com escala expandida. Nas amostras pré-secas determinaram-se a matéria seca em estufa a $105^{\circ} \mathrm{C}$ (CUNNIFF, 1995) e os carboidratos totais solúveis em álcool (Bailey, 1967), conforme citado por VALADARES FILHO (1981).

As porcentagens de colmo, folhas e panícula, na matéria natural (MN) e na matéria seca (MS), e do controle (planta inteira) dos três híbridos encontramse na Tabela 1.

Os valores de $\mathrm{pH}$ e $\mathrm{N}-\mathrm{NH}_{3}$ foram submetidos à análise de variância e comparação de médias, pelo teste SNK (Student Newman Keuls) a 5\% de probabilidade. Com os dados de MS e carboidratos solúveis realizouse análise de regressão polinomial, utilizando o programa computacioanal SAEG (EUCLYDES, 1983).

\section{Resultados e Discussão}

Observa-se, na Tabela 1, que o híbrido granífero (H1) apresentou alta porcentagem de panicula $(59,36)$ e baixa porcentagem de colmo e folhas $(26,56$ e $14,08 \%$, respectivamente), quando comparado com os híbridos de duplo propósito (H2) e forrageiro (H3), que apresentaram proporções de colmo e panícula semelhantes, em base da matéria seca. Se as comparações entre os híbridos $\mathrm{H} 2$ e $\mathrm{H} 3$, em relação as porcentagens das várias partes da planta, forem realizadas com base na matéria natural, o híbrido de porte médio (H2) possui tendência de maior participação de panícula $(23,30 \%)$ e folhas $(18,03 \%)$ e tendência de menor participação de colmo $(58,67 \%)$ na planta inteira que o híbrido de porte alto (H3), o qual possui 18,$08 ; 11,02 ;$ e $70,89 \%$ de panícula, folhas e colmo, respectivamente. Estas comparações poderiam levar à falsa conclusão de que H2 seria nutricionalmente superior a $\mathrm{H} 3$, porque as panículas e as folhas são componentes da planta que apresentam maiores coeficientes de digestibilidade (ZAGO, 1991). Contudo, quando as porcentagens das partes da planta são relacionadas em MS, os teores de panícula e colmo dos híbridos H2 e H3 são semelhan-

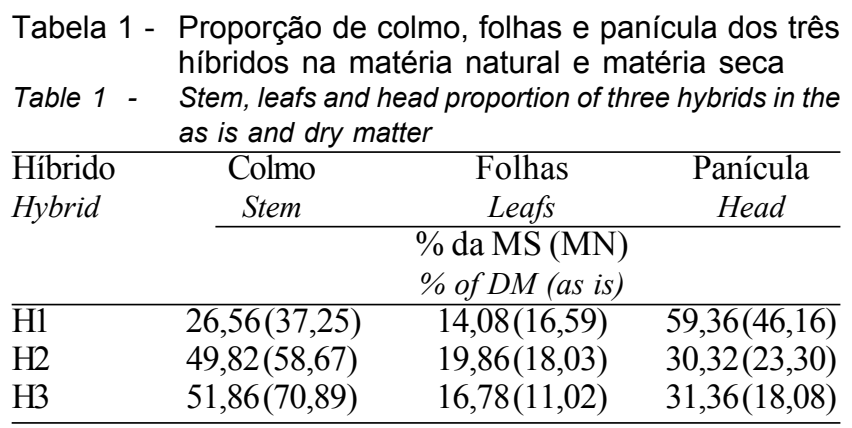

tes, ressaltando dessa forma a importância de fazer sempre as comparações entre híbridos com base na MS, pois a MS é a porção que, nutricionalmente, mais interessa ao ruminante. No trabalho de PEREIRA et al. (1993), as panículas representaram 11,2; 18,5; e 28,5\% do peso total da matéria verde ensilada, respectivamente, para os sorgos de portes alto, médio e baixo.

No controle (planta inteira) do material original, o híbrido granífero (H1) apresentou o maior teor de MS $(37,8 \%)$, seguido pelo híbrido duplo propósito $(\mathrm{H} 2)$ $(31,85 \%)$ e pelo híbrido forrageiro (H3), que apresentou o menor teor de MS (24,69\%); resultados semelhantes aos encontrados no tratamento testemunha das silagens. O híbrido forrageiro possui colmo suculento e os demais, colmo seco. Diferentemente do encontrado neste experimento, BORGES (1995), NOGUEIRA (1995) e BERNARDINO (1996), utilizando a mesma metodologia para determinação dos teores de MS e trabalhando com sorgos de portes alto, baixo e médio, respectivamente, todos de colmo seco e suculento, observaram que os sorgos de colmo seco não apresentaram teores superiores de MS, à colheita, aos sorgos de colmo suculento.

A porcentagem de panícula, 46,16;23,3; e 18,08\% dos híbridos granífero, duplo propósito e forrageiro, respectivamente (Tabela 1), foi a principal responsável pelas diferenças nos teores de MS dos híbridos estudados, pois o aumento da MS na panícula, que ocorre com a maturação, tende a minimizar a interferência da MS do colmo na MS total (CARVALHO et al., 1992). No tratamento sem panícula, o híbrido forrageiro obteve o menor teor de MS (19,37\%), superado pelos demais $(29,41$ e $26,7 \%$, granífero e duplo propósito, respectivamente). Houve tendência linear de aumento do teor de MS com o aumento da participação da panícula nos tratamentos, para os três híbridos, conforme pode ser visto na Figura 1. O maior teor de MS ocorreu no tratamento com $100 \%$ de panícula: 48,32;44,78; e 48,67\%, respectivamente, para 


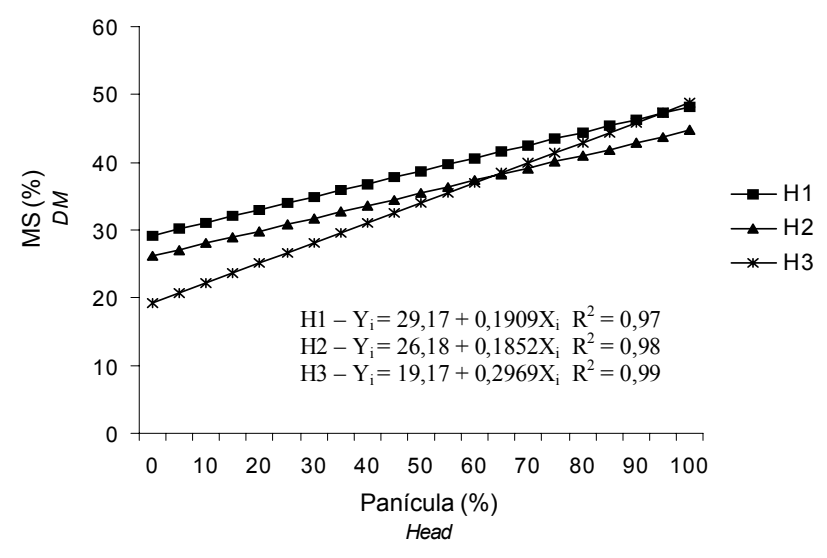

Figura 1 - Influência da porcentagem de panícula nos valores de matéria seca (MS) das silagens.

Figure 1 - Effects of the percentage of head on dry matter (DM) values of silages.

$\mathrm{H} 1, \mathrm{H} 2$ e H3. As proporções influenciaram de forma semelhante os teores de MS do material original e das silagens dos três híbridos. CARVALHO et al. (1992), estudando a composição do sorgo nos estádios de grãos pastosos, farináceos e duros, obtiveram teores de MS de 40,0; 55,98; e 69,40\% para as panículas, respectivamente. A panícula é, sem dúvida, a fração que mais contribui para o aumento do teor de MS da planta.

Silagens feitas de forragens com teores de MS mais elevados $(>40 \%)$ podem apresentar maior dificuldade de compactação e, conseqüentemente, silagem de menor qualidade, devido à maior presença de ar. Segundo VAN SOEST (1994), materiais com maior teor de umidade são mais fáceis de serem compactados. Isto pode ser confirmado observandose a densidade dos silos $\left(\mathrm{kg} / \mathrm{m}^{3}\right)$ do tratamento testemunha (Tabela 2), em que H3, que possui menor teor de MS (Figura 1), tendeu a apresentar maior densidade $\left(756 \mathrm{~kg} / \mathrm{m}^{3}\right)$, comparado aos outros dois híbridos (542 e $601 \mathrm{~kg} / \mathrm{m}^{3}$ para $\mathrm{H} 1$ e $\mathrm{H} 2$, respectivamente), que possuem maiores teores de MS. Entretanto, de forma semelhante aos três híbridos, o incremento dos teores de MS com o aumento da participação da panícula na planta, ao contrário do esperado, facilitou bastante a compactação, conforme pode ser visto na Tabela 2. Provavelmente, a maior responsável pela variação da densidade seja a participação da panícula, fração esta muito densa, que facilita a compactação, pois outros fatores que exercem influência sobre a densidade, como tamanho de partícula e intensidade de compactação, foram relativamente estáveis.

Os teores de nitrogênio amoniacal, em porcenta-
Tabela 2 - Densidade das silagens $\left(\mathrm{kg} / \mathrm{m}^{3}\right)$

Table 2 - Silages density

Híbrido Relação colmo+folhas/panícula

Hybrid Stem+leafs/head proportion

\begin{tabular}{lccccccc} 
& $00: 100$ & $20: 80$ & $40: 60$ & $60: 40$ & $80: 20$ & $100: 00$ & P.Inteira \\
& & & & & & & W. plant \\
\hline H1 & 775 & 650 & 547 & 478 & 454 & 393 & 542 \\
H2 & 798 & 753 & 651 & 608 & 555 & 519 & 601 \\
H3 & 857 & 815 & 757 & 779 & 760 & 731 & 756 \\
\hline
\end{tabular}

gem do nitrogênio total ( $\mathrm{N}-\mathrm{NH}_{3} / \mathrm{NT}$ ) (Tabela 3), foram analisados nos sucos das silagens para possibilitar avaliação do grau de degradação de aminoácidos. $\mathrm{O}$ mais alto teor de $\mathrm{N}-\mathrm{NH}_{3} / \mathrm{NT}$ encontrado neste experimento $(7,91 \%)$ está abaixo dos níveis máximos recomendados pela literatura para silagem de boa qualidade, que variam de 8 a $11 \%$ (OHSHIMA e McDONALD, 1978; AFRC, 1987; HENDERSON, 1993). Silagens de boa qualidade são baixas em amônia e os aminoácidos constituem a maior parte da fração nitrogenada não-protéica (VAN SOEST, 1994).

Os resultados de $\mathrm{N}-\mathrm{NH}_{3} / \mathrm{NT}$ da planta inteira foram semelhantes aos $4,88 \%$ obtidos com sorgos forrageiros por BORGES (1995) e bem superiores aos encontrados por NOGUEIRA (1995) e BERNARDINO (1996), que não ultrapassaram 2,5\% para sorgos de portes baixo e médio, respectivamente. Para os híbridos graníferos e duplo propósito, os maiores teores de $\mathrm{N}-\mathrm{NH}_{3} / \mathrm{NT}$, os quais foram observados nas silagens com $0 \%$ de panícula, foram reduzidos com o aumento da participação da panícula, provavelmente em virtude do aumento do teor de MS. Foi observada, também, correlação negativa baixa, mas significativa $(\mathrm{P}<0,05 ; \mathrm{r}=-0,25)$ entre os teores de N-NH/NT e MS. Entre as proporções do híbrido H3, não houve diferença nas porcentagens de N-NH $3 / \mathrm{NT}$. Apesar dos baixos conteúdos de MS dos tratamentos com 0 e $20 \%$ de panícula do $\mathrm{H} 3$, provavelmente os altos teores de carboidratos solúveis destes tratamentos (Figura 2) não permitiram que houvesse desvios na fermentação lática, com proteólise e degradação de aminoácidos, conforme observado por MEESKE et al. (1993), quando ensilaram sorgo forrageiro.

Os valores de $\mathrm{pH}$ de todas as silagens, apresentados na Tabela 4, estiveram dentro da faixa de $\mathrm{pH}$ considerada normal $(3,6-4,2)$, para que sejam consideradas de boa qualidade (McDONALD et al., 1991). No abaixamento do $\mathrm{pH}$ das silagens, postula-se a participação da fermentação de carboidratos adicionais oriundos da hidrólise da hemicelulose e da celulose (McDONALD et al., 1991), visto que os teores 
Rev. bras. zootec.

Tabela 3 - Teores de nitrogênio amoniacal das silagens, em porcentagem do nitrogênio total Table 3 - Silages ammonia nitrogen content, in percentage of the total nitrogen

\begin{tabular}{|c|c|c|c|c|c|c|c|c|}
\hline \multirow{3}{*}{$\begin{array}{l}\text { Tempo } \\
\text { Time }\end{array}$} & \multirow{3}{*}{$\begin{array}{c}\text { Híbrido }^{2} \\
\text { Hybrid }\end{array}$} & \multicolumn{7}{|c|}{ Relação colmo+folhas/panícula ${ }^{1}$} \\
\hline & & \multicolumn{7}{|c|}{ Stem + leafs/head proportion } \\
\hline & & $00: 100$ & $20: 80$ & $40: 60$ & $60: 40$ & $80: 20$ & $100: 00$ & $\begin{array}{l}\text { P.Inteira } \\
W \text {. plant }\end{array}$ \\
\hline \multirow{3}{*}{56} & $\mathrm{H} 1$ & $5,24 \mathrm{Ca}$ & $5,20 \mathrm{Cb}$ & $5,20 \mathrm{Ca}$ & $5,83 \mathrm{Ca}$ & $6,79 \mathrm{Ba}$ & 7,91Aa & $5,65 \mathrm{Ca}$ \\
\hline & $\mathrm{H} 2$ & $3,17 \mathrm{Db}$ & $2,99 \mathrm{Dc}$ & $3,28 \mathrm{Db}$ & $4,21 \mathrm{Cb}$ & $5,27 \mathrm{Bb}$ & $6,35 \mathrm{Ab}$ & $4,55 \mathrm{Cb}$ \\
\hline & $\mathrm{H} 3$ & $5,89 \mathrm{a}$ & $5,84 \mathrm{a}$ & $5,55 \mathrm{a}$ & $5,24 \mathrm{a}$ & $5,26 \mathrm{~b}$ & $6,09 b$ & $5,16 \mathrm{ab}$ \\
\hline
\end{tabular}

Tabela 4 - Valores de $\mathrm{pH}$ das silagens Table 4 - Silages $\mathrm{pH}$ values

\begin{tabular}{|c|c|c|c|c|c|c|c|c|}
\hline \multirow[t]{2}{*}{$\begin{array}{l}\text { Tempo } \\
\text { Time }\end{array}$} & \multirow[t]{2}{*}{$\begin{array}{c}\text { Híbrido }^{2} \\
\text { Hybrid }\end{array}$} & \multicolumn{7}{|c|}{$\begin{array}{l}\text { Relação colmo+folhas/panícula }{ }^{1} \\
\text { Stem }+ \text { leafs/head proportion }\end{array}$} \\
\hline & & $00: 100$ & $20: 80$ & $40: 60$ & $60: 40$ & $80: 20$ & $100: 00$ & $\begin{array}{l}\text { P.Inteira } \\
W . \text { plant }\end{array}$ \\
\hline & H1 & 3,89 & 3,95 & 3,81 & 3,87 & $3,85 a$ & $4,01 \mathrm{a}$ & $4,16 a$ \\
\hline 56 & $\mathrm{H} 2$ & 3,90 & 3,75 & 3,61 & 3,65 & $3,62 b$ & $3,70 b$ & $3,70 \mathrm{~b}$ \\
\hline & $\mathrm{H} 3$ & 3,93 & 3,80 & 3,78 & 3,72 & $3,62 b$ & $3,61 b$ & $3,70 b$ \\
\hline
\end{tabular}

${ }^{1}$ Médias, na coluna, seguidas por letras minúsculas diferentes são diferentes (entre híbridos) $(P<0,05)$.

${ }^{1}$ Means, within a column, followed by different small letters are different (among hybrids) $(P<.05)$.

$\mathrm{CV}=3,70 \%$.

de carboidratos solúveis da maioria dos tratamentos se encontraram abaixo dos níveis considerados ideais (6 a 8\%), para rápida e desejada queda dos valores de pH (GOURLEY e LUSK, 1977). Os resultados de $\mathrm{pH}$ das silagens analisadas neste trabalho foram semelhantes aos de sorgo forrageiro $(3,4$ a 4,2), avaliados por GAGGIOTTI et al. (1992). BORGES (1995), NOGUEIRA (1995) e BERNARDINO (1996), trabalhando com silagens de sorgo de portes alto, baixo e médio, respectivamente, encontraram valores de $\mathrm{pH}$ de 3,$6 ; 3,7$; e 3,73, respectivamente. HART (1990), porém, ensilando sorgo granífero com teores de MS superiores a 35\%, obteve valores de $\mathrm{pH}$ das silagens de 4,19 a 4,39.

Com o aumento da participação das panículas nas plantas, os teores de MS elevaram-se e não houve aumento nos valores de $\mathrm{pH}$ com a elevação dos teores de MS, embora tenha sido encontrada correlação positiva $(\mathrm{P}<0,01, \mathrm{r}=0,40)$ entre $\mathrm{pH}$ e teor de MS.

Os teores de carboidratos solúveis dos híbridos de duplo propósito e forrageiro, encontrados nos materiais antes da ensilagem, demonstraram característica de redução, com o aumento da participação da panícula na planta (Figura 2), o que era esperado, pois de acordo com McBEE e MILLER (1982) os carboidratos solúveis concentram-se, principalmente, no colmo.
Contudo, para o híbrido granífero (H1) o ${ }^{2}$ da equação de regressão encontrado foi muito baixo $(-0,03)$, não sendo observada diferença nos teores de carboidratos solúveis entre proporções, possuindo variação de 2,24 a 3,56 \%. Na maioria dos tratamentos, os valores de carboidratos solúveis do material

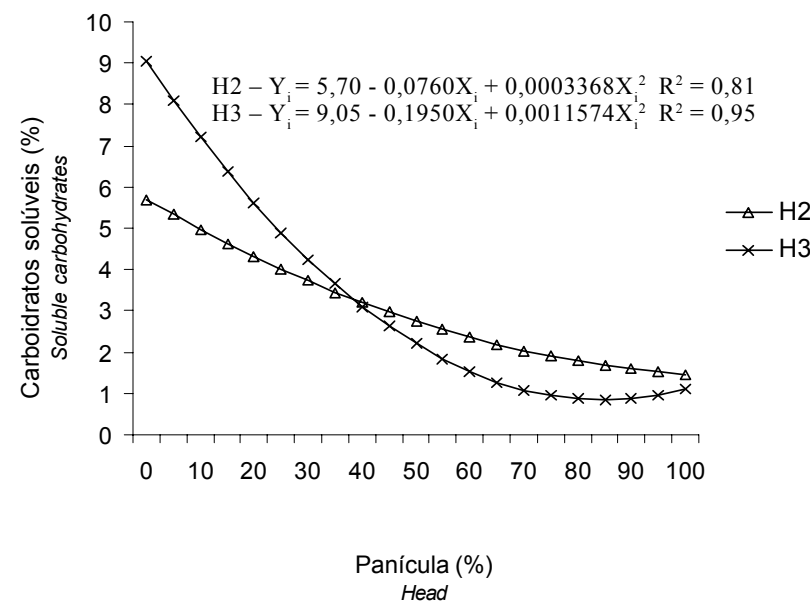

Figura 2 - Influência da porcentagem de panícula nos valores de carboidratos solúveis dos materiais originais.

Figure 2 - Effects of the percentage of head on soluble carbohydrates values of the original materials. 
original estão abaixo dos níveis considerados suficientes (6 a 8\%) para fermentação predominantemente homolática, com rápida queda de $\mathrm{pH}$ (McCullough, 1973, apud GOURLEY e LUSK, 1977), à exceção dos tratamentos com 80 e $100 \%$ de colmo+folhas do híbrido $\mathrm{H} 3$, que apresentaram níveis considerados satisfatórios para boa fermentação. Além das variações existentes entre as espécies, os fatores que mais influenciam o conteúdo de carboidratos solúveis são diferenças entre cultivares, estádio de maturação, tempo de luz, intensidade de luz, temperatura, aplicação de fertilizantes e precipitação pluviométrica (McDONALD et al., 1991). O aumento da temperatura ambiente reduz os valores de carboidratos solúveis na planta (McDONALD et al., 1991) e precipitações fortes durante o crescimento têm causado reduções pela metade nos teores de carboidratos solúveis (Woolford, 1984, citado por HAIGH, 1990). Estes fatores podem ser responsáveis pelos baixos teores de carboidratos solúveis na maioria dos tratamentos estudados. Aos 56 dias de ensilagem, boa parte dos carboidratos solúveis foi utilizada na fermentação, caracterizada pela nítida redução dos teores de carboidratos residuais, com valores inferiores a $1,44 \%$.

Não foi encontrada, neste experimento, correlação significativa entre carboidratos solúveis e $\mathrm{pH}$, indicando que a utilização dos mesmos contribuiu para a qualidade da fermentação, não sendo, portanto, fator limitante.

\section{Conclusões}

Embora os valores de carboidratos solúveis mensurados tenham sido muito baixos para a maioria das silagens, o pH e o nitrogênio amoniacal das silagens foram reduzidos, sendo indicativos de boa fermentação, independente do tipo de sorgo e das proporções de colmo+folhas/panícula.

\section{Referências Bibliográficas}

AFRC Technical Committee on Responses to Nutrients. 1987. Report n.2, Characterisation of feedstuffs: nitrogen. Nutr. Abstr. Rev., Ser. B, 57(12):713-736.

ALVARENGA, M.C.V. Consumo e digestibilidade aparente de silagens de sorgo (Sorghum vulgare Pers) em três momentos de corte e dois tamanhos de partículas, em carneiros. Belo Horizonte, MG, UFMG, 1993. 82p. Dissertação (Mestrado em Zootecnia) - Escola de Veterinária da Universidade Federal de Minas Gerais, 1993.

BERNARDINO, M.L.A. Avaliação nutricional de silagens de hibridos de sorgo (Sorghum bicolor (L.) Moench) de porte médio com diferentes teores de taninos e suculência no colmo. Belo Horizonte, MG, UFMG, 1996. 87p. Dissertação (Mestrado em Zootecnia) - Escola de Veterinária da Universidade Federal de Minas Gerais, 1996.

BORGES, A.L.C.C. Qualidade de silagens de híbridos de sorgo de porte alto, com diferentes teores de tanino e de umidade no colmo, e seus padrões de fermentação Belo Horizonte, MG, UFMG, 1995. 104p. Dissertação (Mestrado em Zootecnia). Escola de Veterinária da Universidade Federal de Minas Gerais, 1995.

CARVALHO, D.D., ANDRADE, J.B., BIONDI, P. et al. 1992. Estádio de maturação na produção e qualidade da silagem de sorgo. I. Produção de matéria seca e da proteína bruta. Bol. Ind. Anim., 49(2):91-99.

CUNNIFF, P. (Ed.). 1995. Official methods of analysis of AOAC International. 16 ed., Arlington: AOAC International. v.1.

EUCLYDES, R.F. Manual de utilização do programa SAEG (Sistema de análise estatística e genética). Viçosa, MG: UFV, 1983, 59p.

GAGGiotTi, M.C., ROMERO, L.A., BRUNO, O.A. et al. 1992. Cultivares de sorgos forrajeros para silaje. II - Características fermenativas y nutritivas de los silajes. Rev. Arg. Prod.Anim., 12(2):163-167.

GOURLEY, L.M., LUSK, F.W. Sorghum silage quality as affected by soluble carbohydrate, tannins and other factors. In: ANNUAL CORN AND SORGHUM RESEARCH CONFERENCE, 32, 1977, Mississipi. Proceedings... Mississipi: Mississipi State University, 1977. p.157-170.

HAIGH, P.M. 1990. Effect of herbage water-soluble carbohydrate content and weather conditions at ensilage on the fermentation of grass silages made on commercial farms. Grass Forage Sci., 45(3):263-271.

HART, S.P. 1990. Effects of altering the grain content of sorghum silage on its nutritive value. J. Anim. Sci., 68(11):3832-3842.

HENDERSON, N. 1993. Silage additives. Anim. Feed Sci. Technol., 45(1):35-56.

LINDEN, J.C., HENK, L.L., MURPHY, V.G. et al. 1987. Preservation of potential fermentables in sweet sorghum by ensiling. Biotecnol. Bioeng., 30(7):860-867.

McBEE, G.G., MILLER, F.R. 1982. Carbohydrates in sorghum culms as influenced by cultivars, spacing, and maturity over a diurnal period. Crop Sci., 22(1-2):381-385.

McDONALD, P., HENDERSON, A.R., HERON, S. 1991. The biochemistry of silage. 2 ed. Marlow: Chalcombe Publications. 340p.

McKERSIE, B.D. Effect of $\mathrm{pH}$ on proteolysis in ensiled legume forage. Agron. J., 77(1):81-86, 1985.

MEESKE, R., ASHBELL, G., WEINBERG, Z.G. et al. Ensiling forage sorghum at two stages of maturity with the addition of lactic acid bacterial inoculants. Anim. Feed Sci. Technol., 43(3/4):165-176, 1993.

NOGUEIRA, F.A.S. Qualidade das silagens de híbridos de sorgo de porte baixo com e sem teores de taninos e de colmo seco e suculento, e seus padrões de fermentação, em condições de laboratório. Belo Horizonte, MG, UFMG, 1995. 78p. Dissertação (Mestrado em Zootecnia). Escola de Veterinária da Universidade Federal de Minas Gerais, 1995.

OSHIMA, V., McDONALD, P. 1978. A review of the changes in nitrogenous compounds of herbage during ensilage. J. Sci. Food. Agric., 29(6):497-505.

PAIVA, J.A.J. Qualidade da silagem da região metalúrgica de Minas Gerais. Belo Horizonte, MG, UFMG, 1976. 85p. Dissertação (Mestrado em Zootecnia) - Escola de Veterinária da UFMG, 1976.

PEREIRA, J.C., OBEID, J.A., GOMIDE, J.A. et al. 1993. Produtividade de uma variedade de milho (Zea mays L.) e de 
20 Rev. bras. zootec.

três variedades de sorgo (Sorghum bicolor (L.) Moench) e o valor nutritivo de suas silagens. R. Soc. Bras. Zootec., 22(1):31-38.

PEREIRA, J.C., OBEID, J.A., BARBOSA, P.D. 1989. Influência do espaçamento e da adubação nitrogenada sobre a produção e o teor de proteína bruta do sorgo forrageiro (Sorghum bicolor (L.) var. Sart). R. Soc. Bras. Zootec., 18(6):468-472.

SILVA, B.G., COELHO, A.M., SILVA, A.F. et al. 1978. Sistemas de produção de milho e sorgo para silagem. Inf. Agropec., 47(4):3-5.

VALADARES FILHO, S.C. Digestibilidade aparente e locais de digestão da matérai seca, energia e carboidratos de fenos de soja perene. Belo Horizonte: Escola de Veterinária da UFMG, 1981. 88p. Dissertação (Mestrado em Zootecnia) - Universidade Federal de Minas Gerais, 1981.
VAN SOEST, P.J. 1994. Nutritional ecology of the ruminant. 2 ed. Ithaca, New York: Cornell University Press. 476p.

ZAGO, C.P. Cultura de sorgo para produção de silagem de alto valor nutritivo. In: SIMPÓSIO SOBRE NUTRIÇÃO DE BOVINOS, 4, 1991, Piracicaba. Anais... Piracicaba: FEALQ, 1991. p.169-217.
Recebido em: 08/03/97

Aceito em: 09/09/98 